\title{
Opposing effects on muscarinic acetylcholine receptors in the piriform cortex of odor-trained rats
}

\author{
Drorit Saar, ${ }^{1}$ Moran Dadon, Marcela Leibovich, Hagar Sharabani, Yoram Grossman, \\ and Eliahu Heldman
}

\author{
Department of Physiology, Faculty for Health Sciences and Zlotowski Center for Neuroscience, Ben-Gurion University of the \\ Negev, Beer-Sheva 84105, Israel
}

\begin{abstract}
We combined pharmacological studies and electrophysiological recordings to investigate modifications in muscarinic acetylcholine $(A C h)$ receptors $(m A C h R)$ in the rat olfactory (piriform) cortex, following odor-discrimination rule learning. Rats were trained to discriminate between positive and negative cues in pairs of odors, until they reached a phase of high capability to learn unfamiliar odors, using the same paradigm ("rule learning"). It has been reported that at 1-3 d after the acquisition of odor-discrimination rule learning, pyramidal neurons in the rat piriform cortex show enhanced excitability, due to a reduction in the spike-activated potassium current $\mathrm{I}_{\mathrm{AHP}}$, which is modulated by $\mathrm{ACh}$. Further, $\mathrm{ACh}$ and its analog, carbachol $(\mathrm{CCh})$, lost the ability to reduce the $\mathrm{I}_{\mathrm{AHP}}$ in neurons from trained rats. Here we show that the reduced sensitivity to $\mathrm{CCh}$ in the piriform cortex results from a decrease in the number of $\mathrm{mAChRs}$, as well as a reduction in the affinity of the receptors to $\mathrm{CCh}$. Also, it has been reported that 3-8 $\mathrm{d}$ after the acquisition of odor-discrimination rule learning, synaptic transmission in the piriform cortex is enhanced, and paired-pulse facilitation (PPF) in response to twin stimulations is reduced. Here, intracellular recordings from pyramidal neurons show that CCh increases PPF in the piriform cortex from odor-trained rats more than in control rats, suggesting enhanced effect of $\mathrm{ACh}$ in inhibiting presynaptic glutamate release after odor training.
\end{abstract}

Behavioral studies show that rats can be trained to discriminate between positive and negative cues in pairs of odors (Staubli et al. 1986; Saar et al. 1998, 1999; Sara et al. 1999). The process of learning to discriminate between two odors requires between seven and nine consecutive days of training. However, once the rat has acquired this ability, the learning process of discriminating between additional pairs of odors is greatly facilitated ("rule learning"). This phase of high learning capability lasts for 7-8 d without further training (Staubli et al. 1986; Saar et al. 1998, 1999). Odor-discrimination learning involves the piriform cortex, which receives incoming information directly from the olfactory bulb. Sensory input arriving via the lateral olfactory tract is widely spread across the entire surface of the piriform cortex, such that unitary odorant stimulation activates a large population of neurons in this region (Schoenbaum and Eichenbaum 1995). The piriform cortex has a simple and defined anatomical organization (Price 1973; see diagram in Fig. 1C), including a thin layer of densely packed pyramidal cell bodies (layer II), which is easily visualized under the microscope. Intracellular recordings from this homogenous population of neurons enable statistical comparisons between different groups of rats. Also, the segregation between intra-cortical association axons, which synapse on layer II neurons in layer Ib, and the afferent inputs from the olfactory bulbs, which synapse at layer Ia, enable comparison of synaptic responses in association with specific input pathways.

We have previously shown that odor learning induces enhanced membrane excitability and increased synaptic transmission between layer II pyramidal neurons in the rat piriform cortex (Saar et al. 1998, 1999). Cholinergic activity is essential for learning in a range of behavioral tasks (Sutherland et al. 1982; Hagan and Morris 1989; Hasselmo 1995). In this context, we have shown that, in the piriform cortex from odor-trained rats,

\section{${ }^{1}$ Corresponding author.}

E-mail drorit@bgu.ac.il; fax 972-8-6477628.

Article is online at http://www.learnmem.org/cgi/doi/10.1101/lm.452307. carbachol (CCh) loses its ability to increase membrane excitability in layer II pyramidal neurons (Saar et al. 2001). In the present study we have used acetylcholine (ACh) agonists and antagonists to study the mechanism of learning-induced reduction in postsynaptic sensitivity to ACh. Also, we used intracellular recordings in brain slices to examine whether ACh ability to modulate synaptic transmission between pyramidal neurons in the piriform cortex (Hasselmo and Bower 1992) is modified after odor training.

\section{Results}

\section{Odor learning}

As previously reported (Saar et al. 1998, 1999, 2001), acquisition of the first discrimination task required an average of seven to nine training days. However, learning to distinguish between additional pairs of odors with the same paradigm was much faster, requiring only one to two learning days (Fig. 1B). This phenomenon suggests that training to distinguish between odors is associated not only with memory acquisition of specific odors, but also with learning of the paradigm rules (odor-discrimination rule learning, ODRL).

Binding of ${ }^{3} \mathrm{H}-\mathrm{NMS}$ to $\mathrm{mAChR}$ is reduced after ODRL To examine the effect of odor learning on the features of muscarinic acetylcholine receptors (mAChR) in the piriform cortex, we studied the binding of radioactive $\mathrm{N}$-methyl-scopolamine $\left({ }^{3} \mathrm{H}-\mathrm{NMS}\right)$, a specific mAChR antagonist, to homogenates taken from the piriform cortex after odor training. In order to examine whether odor training affects specifically the brain region which is involved in the odor information processing, we have tested also another region of the cerebral cortex, the visual cortex. In homogenates of the piriform cortex, the maximal specific binding of ${ }^{3} \mathrm{H}-\mathrm{NMS}$ was significantly lower $(P<0.01)$ after ODRL $(11.08 \pm 0.78 \mathrm{fmol} / \mathrm{mg}$ tissue, mean $\pm \mathrm{SE}, n=29 \mathrm{rats})$ compared 
A
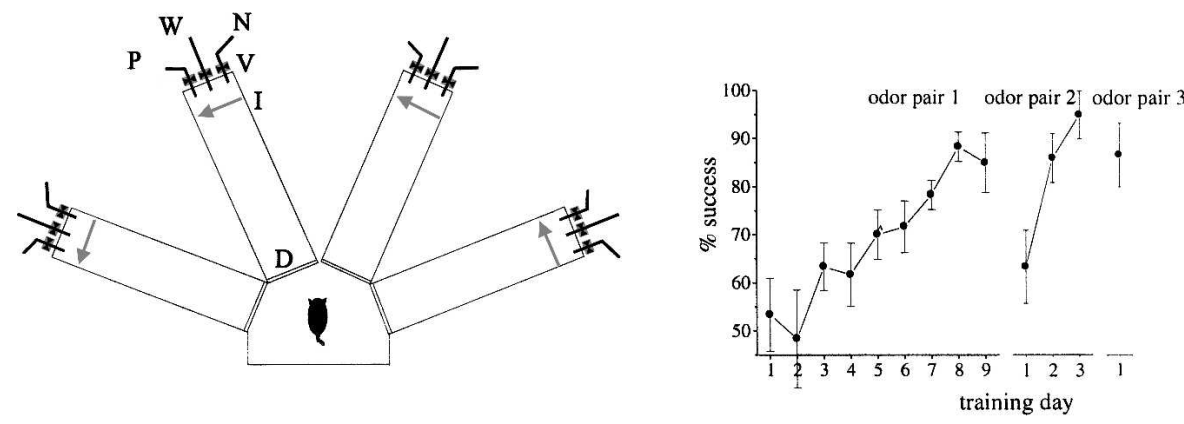

C

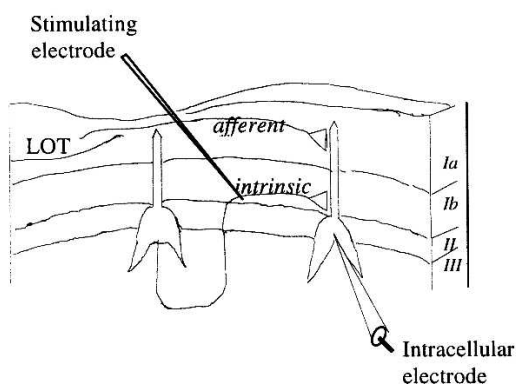

B

D

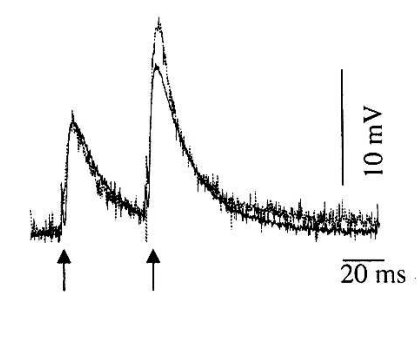

Figure 1. Training for odor discrimination and recording from cortical brain slices. (A) Schematic description of the four-arm maze. Protocols for trained and pseudo-trained rats were similar: An electronic "start" command opens randomly two of eight valves $(V)$, releasing a positive-cue odor (P) into one of the arms and a negative-cue odor $(\mathrm{N})$ into another. Eight seconds later, the two corresponding guillotine doors (D) are lifted to allow the rat (at the starting point, rat silhouette) to enter the selected arms. After reaching the far end of an arm ( $90 \mathrm{~cm}$ long), the rat body interrupts an infrared beam (I, arrow), and a drop of drinking water is released from a water hose (W) into a small drinking well (for a trained rat, only if the arm contains the positive-cue odor; for a pseudo-trained rat, randomly). A trial ends when the rat interrupts a beam, or in $10 \mathrm{sec}$ if no beam is interrupted. A fan is operated for $15 \mathrm{sec}$ between trials to remove odors. (B) Odor-discrimination rule learning. Eight consecutive days of training were required for this group of rats to reach criterion for discriminating between the first pair of odors ( $80 \%$ correct choices). Discrimination of the second pair of odors could be reached within $2 \mathrm{~d}$. Values represent mean \pm SE. $n=6$ rats. (C) Schematic illustration of the piriform cortex slice and the experimental procedure. Stimulating electrode was placed in layer Ib to stimulate the intrinsic connection between layer II pyramidal neurons. Intracellular recordings were performed from cell bodies in layer II. (D) Representative responses in layer II pyramidal neuron to a pair of stimuli (arrows) applied in layer lb before (continues trace) and after (dotted trace) CCh application. Stimulus intensity was adjusted to generate a 10-mV first response in each pair.

to the pseudo-trained rats $(16.06 \pm 1.01 \mathrm{fmol} / \mathrm{mg}$ tissue, $n=29$ rats) and to the naïve rats $(15.43 \pm 1.15 \mathrm{fmol} / \mathrm{mg}$ tissue, $n=27$ rats). The values obtained from the pseudo-trained and the naïve rats were not significantly different from each other (Fig. 2). These findings suggest that ODRL is accompanied by a reduction in the number of $\mathrm{mAChR}$ in the piriform cortex. In homogenates from the visual cortex, the maximal specific binding of ${ }^{3} \mathrm{H}-\mathrm{NMS}$ was not significantly different between trained rats $(16.06 \pm 0.68 \mathrm{fmol} / \mathrm{mg}$ tissue, mean $\pm \mathrm{SE}, n=6)$, pseudotrained rats $(16.70 \pm 3.31 \mathrm{fmol} / \mathrm{mg}$ tissue, $n=5)$, and naïve rats $(16.34 \pm 1.66 \mathrm{fmol} / \mathrm{mg}$ tissue, $n=5)$. These findings suggest that the reduction in the number of the $\mathrm{mAChR}$ following odor training is specific and confined to the brain region which is involved in the odor information processing, namely, the piriform cortex.

\section{The affinity of carbachol to $\mathrm{mAChR}$ is reduced following ODRL}

Since acquisition of ODRL is associated with a reduction in the number of $\mathrm{mAChR}$ in the piriform cortex, we examined if the affinity of the neurotransmitter to the remaining $\mathrm{mAChR}$ is affected as well. Homogenates of the piriform cortex were incu- bated with a fixed concentration of ${ }^{3} \mathrm{H}$ NMS in the presence of increasing concentrations of $\mathrm{CCh}$, between $10^{-9} \mathrm{M}$ and $10^{-2} \mathrm{M}$. The competition curves describing the amount of the bound ${ }^{3} \mathrm{H}$ NMS at each CCh concentration (Fig. 3) were used to calculate $\mathrm{IC}_{50}$ values of $\mathrm{CCh}$ for each of the experimental groups. The $\mathrm{IC}_{50}$ for $\mathrm{CCh}$ in tissue from trained rats was significantly higher $(15.49 \pm 3.49 \mu \mathrm{M}$, mean $\pm \mathrm{SD}, n=5)$ compared to the pseudo-trained rats $(2.47 \pm 0.18 \mu \mathrm{M}, n=6, P<0.001)$ and the naïve rats $(3.17 \pm 0.08 \mu \mathrm{M}, n=5$, $P<0.01$ ), which did not differ significantly from each other. The $K_{i}$ values of $\mathrm{CCh}$ for each of the experimental groups were calculated from the $\mathrm{IC}_{50}$ (based on a $K_{d}$ of $0.2 \mathrm{nM}$ for ${ }^{3} \mathrm{H}-\mathrm{NMS}$, which was determined in preliminary experiments). We found that the $K_{i}$ of CCh for the trained rats $(2.95 \pm 0.66 \mu \mathrm{M}$, mean \pm SEM, $n=5$ ) was significantly higher compared to the pseudo-trained rats $(0.47 \pm 0.03 \mu \mathrm{M}, n=6, P<0.001)$ and naïve rats $(0.60 \pm 0.016 \mu \mathrm{M}, n=5$, $P<0.01$ ), which did not differ significantly from each other.

\section{Paired pulse facilitation (PPF) is enhanced by $\mathrm{CCh}$ more in neurons from trained rats}

We have previously shown that layer II pyramidal neurons exhibit PPF in response to pairs of stimuli applied to the intra-cortical axons in layer $\mathrm{Ib}$, and that PPF was markedly smaller in neurons from trained rats compared to neurons from pseudo-trained and naïve rats (Saar et al. 1999), suggesting enhanced presynaptic release during the first response in a pair (Katz and Miledi 1968; Wu and Saggau 1994). Also, it has been shown that application of $\mathrm{CCh}$ to piriform cortex brain slices causes reduction of the first postsynaptic potential (PSP) and enhancement of PPF (Hasselmo and Bower 1992). To determine whether ODRL changes the modulatory effect of ACh on synaptic release in the piriform cortex, we examined the PPF before and after $\mathrm{CCh}$ application, in brain slices from the three rat groups. In agreement with previous reports (Saar et al. 1999), in normal slice Ringer's (NSR) solution, PPF in response to twin stimulations of the association fibers was significantly smaller in neurons from trained rats $(1.32 \pm 0.04$, mean $\pm \mathrm{SE}, n=8$ neurons from four rats), compared to pseudo-trained rats $(1.44 \pm 0.05, n=12$ neurons from six rats, $P<0.05)$. The difference from naïve rats (1.38 $\pm 0.04, n=6$ neurons from six rats) was not significant due to the small number of neurons used for electrophysiological recording, since a large part of the piriform cortex from each rat was dedicated to the biochemical studies. However, significant reduction in PPF in trained rats compared to naïve rats has been previously reported (Saar et al. 1999). CCh application caused a significant increase in PPF in neurons from all groups (paired $t$-test, $P<0.05)$. However, the increase in PPF was greater in neurons from trained rats, so that the PPF in slices treated with $\mathrm{CCh}$ did not differ from the PPF recorded from neurons of pseudo- 

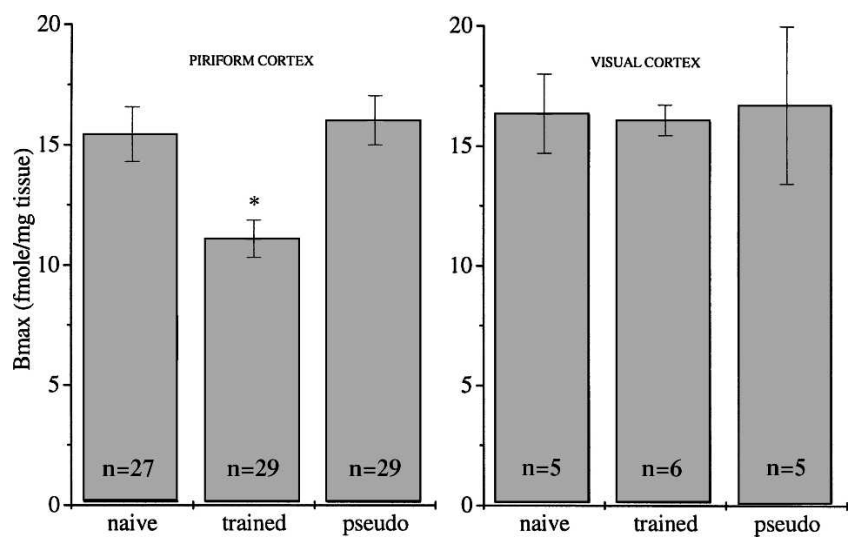

Figure 2. Bmax of ${ }^{3} \mathrm{H}-\mathrm{NMS}$ binding is reduced in the piriform cortex, but not in the visual cortex from trained rats. Bmax was determined $3 \mathrm{~d}$ after the completion of odor training by measuring the binding of saturating concentrations of ${ }^{3} \mathrm{H}-\mathrm{NMS}$ to homogenates taken from the piriform and the visual cortex. Specific binding was determined by subtracting the nonspecific bound ${ }^{3} \mathrm{H}-\mathrm{NMS}$, measured in the presence of $10 \mu \mathrm{M}$ atropine, from the total bound ${ }^{3} \mathrm{H}-\mathrm{NMS}$ measured in the absence of atropine. In the piriform cortex (left), the Bmax value was significantly lower in tissue taken from trained rats compared to the control groups. In the visual cortex (right), the Bmax values were similar for all the experimental groups. Values indicate mean \pm SEM, where $n=29$ trained, 29 pseudo-trained, and 27 naïve rats. ${ }^{*} P<0.002$

trained and naïve rats $(1.57 \pm 0.05$, and $1.47 \pm 0.06$ respectively), as demonstrated in Figure 4 . In particular, in neurons from trained rats PPF was increased by $50 \%$, compared to $29 \%$ and $23 \%$ increase in neurons from pseudo-trained and naïve rats, respectively (see calculations in Materials and Methods). These data suggest that CCh has a stronger effect on synaptic transmission between layer II neurons in the piriform cortex after ODRL.

\section{Discussion}

Reduction in the number of $\mathrm{mAChR}$ following ODRL Several behavioral studies have suggested a role for ACh in the learning of a new task, but not in exercising the same task after acquisition (Aigner et al. 1991; Naor and Dudai 1996; Orsetti et al. 1996; Miranda and Bermudez-Rattoni 1999).

At the cellular level, it has been shown that CCh loses its ability to increase membrane excitability in pyramidal neurons of piriform cortex from odor-trained rats (Saar et al. 2001).

A possible mechanism for the reduced sensitivity to CCh following odor training is a reduction in the number of $\mathrm{mAChR}$ due to receptor internalization. Long-term internalization of ACh receptors, as indicated by the monoclonal antibody M-35, has been shown in rat CA1 following spatial learning (Van der Zee et al. 1995) and following fear conditioning and eye-blink conditioning (for reviews, see van der Zee and Luiten 1999; Van Koppen and Kaiser 2003; Volpicelli and Levey 2004), thus reducing the receptors susceptibility for activation. Here we show that odor learning is also accompanied by a reduction in the number of $\mathrm{mAChR}$, as assessed by binding of ${ }^{3} \mathrm{H}-\mathrm{NMS}$ to homogenates of the piriform cortex, suggesting that acquisition of ODRL is associated with a down-regulation of the mAChR. This downregulation is specific to the piriform cortex and does not occur in the visual cortex, indicating that the process is specific to odor learning and is not a general phenomenon related to the wholebrain activation.

\section{Reduction in the affinity of $\mathrm{CCh}$ to the $\mathrm{mAChR}$ following ODRL}

It has been shown that mAChR may exist in either a high-affinity state, when associated with a G-protein, or in a low-affinity state, when the receptor is uncoupled from the G-protein (Galper and Smith 1980; Burgisser et al. 1982; Waelbroeck et al. 1982; Gurwitz et al. 1984). Transition from the high- to the low-affinity state can be induced by mAChR agonists and by guanine nucleotides (Waelbroeck et al. 1982; Gurwitz et al. 1984). We found that the concentrations of CCh needed to compete with ${ }^{3} \mathrm{H}-\mathrm{NMS}$ for binding to the mAChR in the piriform cortex is increased in trained rats, indicating a reduction in the affinity of ACh to the mAChR. The reduced affinity between the mAChR and the neurotransmitter suggests that ODRL may be associated with an increase in the ratio between the low-affinity, uncoupled $\mathrm{mAChR}$ and the high-affinity, G-protein-coupled mAChR. This change in the proportion between the uncoupled receptors and the coupled receptors is specific to the piriform cortex, the brain region associated with the processing of odor information.

\section{Inhibition of glutamate release by $\mathrm{CCh}$ is enhanced following ORDL}

It has been reported that activation of mAChR causes presynaptic inhibition of excitatory synaptic potentials. This effect was shown to occur in area CA1 by blocking of presynaptic voltagedependent calcium channels (Qian and Saggau 1997). This effect has also been demonstrated in the hippocampal region CA3 (Hasselmo et al. 1995; Vogt and Regehr 2001), as well as in some cortical regions (Brocher et al. 1992; Hasselmo and Cekic 1996; Hess and Krawczyk 1996), including the piriform cortex (Hasselmo and Bower 1992). It has been suggested from realistic modeling of the piriform cortex network that increased suppression of previously potentiated fibers improves the network capability to discriminate between similar patterns. This conclusion was supported by physiological experiments in brain slices of the olfactory cortex, showing that the previously potentiated fibers show significantly greater suppression by CCh than unpotentiated fibers (Linster et al. 2003). Here we show that the same phenomenon is manifested following ODRL, as CCh, the cholinergic agonist, has greater suppressing effect on previously potentiated fibers in the olfactory cortex of odor-trained rats.

\section{Opposing effects of odor training on sensitivity to $\mathrm{CCh}$ in pre-synaptic and postsynaptic sites}

Odor training causes opposing effects on the modulation of electrophysiological responses by ACh in the piriform cortex. These

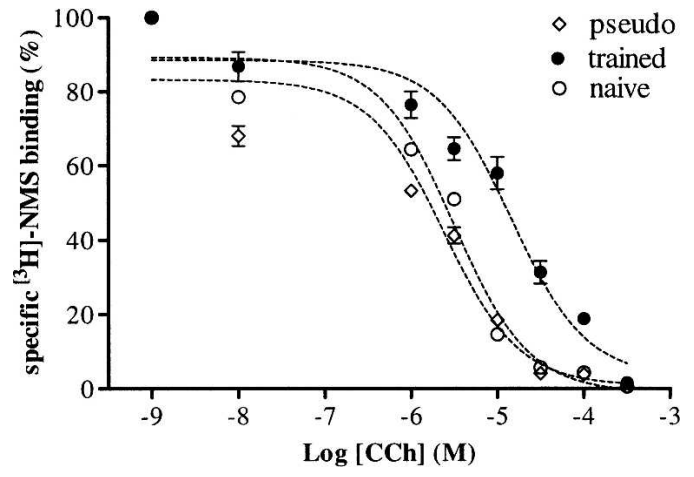

Figure 3. The competition curve of $\mathrm{CCh}$ is shifted to the right in the piriform cortex from trained rats. Piriform cortex homogenates were incubated with a fixed concentration $(0.85 \mathrm{nM})$ of ${ }^{3} \mathrm{H}-\mathrm{NMS}$ in the presence of increasing concentrations of $\mathrm{CCh}$. Binding was normalized relative to the binding obtained in each homogenate in the absence of CCh, which was considered $100 \%$. The competition curves obtained with tissue homogenates from trained rats are shifted to the right, suggesting a reduction in the affinity of CCh to mAChR. Values indicate mean \pm SEM $n=5$ naïve rats, 6 pseudo-trained rats, and 5 trained rats, performed in duplicates.

\section{Learning \& Memory \\ www.learnmem.org}


effects are reduction in postsynaptic sensitivity to CCh, which is indicated by reduced CCh effect on $\mathrm{I}_{\mathrm{AHP}}$ (Saar et al. 2001), and, at the same time, an increase in pre-synaptic sensitivity to CCh, which is indicated by increased effect of CCh on PPF. These opposing effects could be explained by the existence of two different types of ACh receptors at the pre-synaptic and the postsynaptic sites, and these two receptor types are affected differently by odor discrimination training. Indeed, it has been shown in several brain regions that M1 subtype of mAChR is located mostly at postsynaptic sites in synapses containing excitatory amino acids, while $\mathrm{mAChR}$, which are located on axonal terminals, are mostly of subtype M2 or M3 (Mrzljak et al. 1993; Hersch et al. 1994; Levey et al. 1995; Rouse et al. 1999, 2000; Erisir et al. 2001). If this is true for the piriform cortex, our data may suggest that odor training induces a reduction in the sensitivity of the M1 receptors, and enhanced sensitivity of the M2 or M3 receptors and the overall reduction in the number and the affinity of the mAChR may be related to the fact that in most CNS regions M1 postsynaptic receptors are more abundant than the M2 and M3 pre-synaptic receptors (Wei et al. 1994; Oki et al. 2005). However, the exact subtypes of pre- and postsynaptic mAChR in layer II pyramidal neurons in the piriform cortex are yet to be determined.

\section{Materials and Methods}

\section{Animal training}

Young adult (6 wk) water-deprived Sprague-Dawley male rats were trained for odor discrimination in a four-arm maze, with commercial odors that are regularly used in the cosmetics and food industry, as previously described (Saar et al. 1998). In short, for each trial the rat is positioned at the starting point (Fig. 1A, rat silhouette); an electronic "start" command releases two streams of pressured air into two random arms-a stream with positivecue odor into one of the arms and one with negative-cue odor into another; the rat is given the choice of entering two arms and is rewarded at the far end with a drop of drinking water. Rats in the trained group are rewarded only in the arm containing the positive-cue odor. Pseudo-trained rats are rewarded randomly. Naïve rats are water-deprived, but not exposed to the maze. Rats are trained with 20 trials per day, and a fan is operated between trials to clear the air. Once all the trained rats have met the criterion for learning the first pair of odors (at least $80 \%$ positivecue choices in a day), on the next day both trained and pseudotrained groups resume training with a new pair of odors. Rats were trained with at least two pairs of odors to ensure rule learning (Fig. 1B).

\section{Brain slice preparation}

Rats were sacrificed three days after training completion, when learning-induced intrinsic and synaptic modifications in the piriform cortex are both apparent (Saar et al. 1998, 1999). The experimental procedure was reviewed and approved by the ethical committee of the university. Experiments were done blind; the group affiliation of the rats (naïve, trained, or pseudo-trained) was unknown to the person conducting the experiments and measurements. Rats were deeply anesthetized with Pentobarbital (60 mg/kg), the brain was removed into cold physiological solution, and coronal brain slices of $400 \mu \mathrm{m}$ were cut as previously described (Saar et al. 1998). Some of the slices were further dissected under microscope, to isolate the region of interest (piriform cortex, visual cortex), and then frozen at $-80^{\circ} \mathrm{C}$ for pharmacological experiments. The rest of the slices were incubated for $1 \mathrm{~h}$ at room temperature for electrophysiological recordings, in oxygenated $\left(95 \% \mathrm{O}_{2}+5 \% \mathrm{CO}_{2}\right)$ normal slice Ringer's (NSR) solution containing $\mathrm{NaCl} 124 \mathrm{mM}, \mathrm{KCl} 3 \mathrm{mM}, \mathrm{MgSO}_{4} 2 \mathrm{mM}$, $\mathrm{NaH}_{2} \mathrm{PO}_{4} 1.25 \mathrm{mM}, \mathrm{NaHCO}_{3} 26 \mathrm{mM}, \mathrm{CaCl}_{2} 2 \mathrm{mM}$, and glucose $10 \mathrm{mM}$.

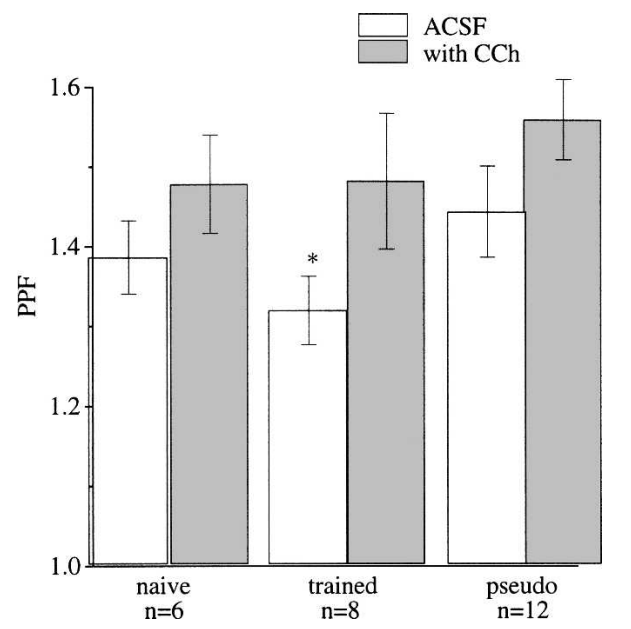

Figure 4. $\mathrm{PPF}$ is enhanced by $\mathrm{CCh}$ more in neurons from trained rats. Pairs of stimuli with ISI $=50 \mathrm{msec}$ were applied to layer $\mathrm{lb}$ before (NSR [ACSF], white columns) and after (gray columns) CCh application. PPF was calculated from the ratio between the amplitudes of the second response and the first response in a pair. With $\mathrm{CCh}$, there was no significant difference in PPF between neurons from the trained group and the control groups. Values indicate mean \pm SEM, $n=$ number of neurons. ${ }^{*} P<0.05$.

\section{Binding features of the muscarinic acetylcholine receptors}

Brain tissue was homogenized at a ratio of 1:10 tissue to homogenizing buffer containing $\mathrm{NaCl} 115 \mathrm{mM}, \mathrm{KCl} 5 \mathrm{mM}, \mathrm{Na}_{2} \mathrm{HPO}_{4} 50$ $\mathrm{mM}, \mathrm{NaH}_{2} \mathrm{PO}_{4} 50 \mathrm{mM}$, EDTA $0.2 \mathrm{mM}$. The homogenates were incubated for one hour with increasing concentrations, between 0 and $1 \mathrm{nM}$ of radioactive N-methyl-scopolamine $\left({ }^{3} \mathrm{H}-\mathrm{NMS}\right)$, a specific muscarinic antagonist. The incubation buffer included $\mathrm{NaCl} 100 \mathrm{mM}, \mathrm{MgCl}_{2} 5 \mathrm{mM}$, and HEPES $20 \mathrm{mM}$. The bound ligand was separated from the free ligand by a rapid filtration over a CF/C glass microfiber filter. Nonspecific binding was obtained by including $10 \mu \mathrm{M}$ atropine in the incubation buffer. Specific binding was determined by subtracting the nonspecific bound ${ }^{3} \mathrm{H}$-NMS from the total bound ${ }^{3} \mathrm{H}-\mathrm{NMS}$ measured in the absence of atropine. Bmax was calculated from the specific ${ }^{3} \mathrm{H}$ NMS binding curves. The affinity of CCh to the mAChR was determined by a competition assay in which the binding of 0.85 $\mathrm{nM}{ }^{3} \mathrm{H}$-NMS was determined in the presence of increasing concentrations of CCh, between $10^{-9} \mathrm{M}$ and $10^{-2} \mathrm{M}$. Values of $K_{i}$ and $\mathrm{IC}_{50}$ were calculated from the competition curves, using the GraphPad Prism 4.0 software.

\section{Electrophysiological recordings}

Brain slices were placed in slice chamber, and perfused with oxygenated NSR at $36^{\circ} \mathrm{C}$. Intracellular recordings were obtained from pyramidal neurons in layer II of the piriform cortex, using $4 \mathrm{M}$ K-acetate-filled sharp electrode. Electrical stimuli were applied via tungsten bipolar microelectrodes, placed in layer Ib, to stimulate the intra-cortical association axons. Electrical stimuli were applied at $0.1 \mathrm{~Hz}$. The amplitude of the postsynaptic potential (PSP) was measured from digital averaging of six consecutive responses. To standardize the intracellular recording conditions, stimulus intensity was adjusted so that the averaged amplitude of six consecutive PSPs would be $10 \mathrm{mV}$ at $V_{\mathrm{m}}=-80 \mathrm{mV}$. Then, the same intensity was used to apply twin stimuli, with interstimulus interval (ISI) of $50 \mathrm{msec}$, to measure paired pulse facilitation (PPF). CCh $(20 \mu \mathrm{M})$ was applied by perfusion until a reduction in the PSP was observed (Hasselmo and Bower 1992). Then, the intensity of the stimulus was adjusted so that the averaged amplitude of six consecutive PSPs in the recorded cell would be $10 \mathrm{mV}$ at $V_{\mathrm{m}}=-80 \mathrm{mV}$, and the same intensity was used to apply twin stimuli, with ISI of 50 msec. The first PSP in a pair was measured from baseline to the peak of voltage deflection. Since the second PSP in a pair often started before the membrane potential returned to baseline, an average of six PSP re- 
sponses to single shock was digitally subtracted from the average of six responses to paired shocks to obtain baseline for measurement of the second response in a pair. PPF was calculated as the ratio between the amplitudes of the second response and the first response in a pair.

\section{Statistical analysis}

Statistical analysis to compare between the three groups (trained, pseudo-trained, and naive) was carried out using one-way ANOVA, with Tukey's multiple comparisons between each two groups. Comparison of PPF within the same group before and after CCh application was done using paired $t$-test. The increase in PPF following CCh application was calculated as follows: $\left(\mathrm{PPF}_{\text {in CCh }}\right)-1 /\left(\mathrm{PPF}_{\text {in NSR }}-1\right) \times 100$.

\section{References}

Aigner, T.G., Walker, D.L., and Mishkin, M. 1991. Comparison of the effects of scopolamine administrated before and after acquisition in a test of visual recognition memory in monkeys. Behav. Neural. Biol. 55: $61-67$.

Brocher, S., Artola, A., and Singer, W. 1992. Agonists of cholinergic and noradrenergic receptors facilitate synergistically the induction of long-term potentiation in slices of rat visual cortex. Brain Res. 573: $27-36$.

Burgisser, E., De Leans, A., and Lefkowitz, R.J. 1982. Reciprocal modulation of agonist and antagonist binding to muscarinic cholinergic receptor by guanine nucleotide. Proc. Natl. Acad. Sci. 79: $1732-1736$.

Erisir, A., Levey, A.I., and Aoki, C. 2001. Muscarinic receptor M(2) in cat visual cortex: Laminar distribution, relationship to $\gamma$-aminobutyric acidergic neurons, and effect of cingulate lesions. J. Comp. Neurol. 441: $168-185$.

Galper, J.B. and Smith, T.W. 1980. Agonist and guanine nucleotide modulation of muscarinic cholinergic receptors in cultured heart cells. J. Biol. Chem. 255: 9571-9579.

Gurwitz, D., Kloog, Y., and Sokolovsky, M. 1984. Recognition of the muscarinic receptor by its endogenous neurotransmitter: Binding of $[3 \mathrm{H}]$ acetylcholine and its modulation by transition metal ions and guanine nucleotides. Proc. Natl. Acad. Sci. 81: 3650-3654.

Hagan, J.J. and Morris, R.G.M. 1989. The cholinergic hypothesis of memory: A review of animal experiments. In Psychopharmacology of the aging nervous system. (eds. L.L. Iversen and S.H. Snyder), pp. 237-324. Plenum, New York.

Hasselmo, M.E. 1995. Neuromodulation and cortical function: Modeling the physiological basis of behavior. Behav. Brain Res. 65: 1-27.

Hasselmo, M.E. and Bower, J.M. 1992. Cholinergic suppression specific to intrinsic not afferent fiber synapses in rat piriform olfactory cortex. J. Neurophysiol. 67: 1222-1229.

Hasselmo, M.E. and Cekic, M. 1996. Suppression of synaptic transmission may allow combination of associative feedback and self-organizing feedforward connections in the neocortex. Behav. Brain Res. 79: 153-161.

Hasselmo, M.E., Schnell, E., and Barkai, E. 1995. Dynamics of learning and recall at excitatory recurrent synapses and cholinergic modulation in hippocampal region CA3. J. Neurosci. 15: 5249-5262.

Hersch, S.M., Gutekunst, C.A., Rees, H.D., Heilman, C.J., and Levey, A.I. 1994. Distribution of m1-m4 muscarinic receptor proteins in the rat striatum: Light and electron microscopic immunocytochemistry using subtype-specific antibodies. J. Neurosci. 14: 3351-3363.

Hess, G. and Krawczyk, R. 1996. Cholinergic modulation of synaptic transmission in horizontal connections of rat motor cortex. Acta Neurobiol. Exp. 56: 863-872.

Katz, B. and Miledi, R. 1968. The role of calcium in neuromuscular facilitation. J. Physiol. 195: 481-492.

Levey, A.I., Edmunds, S.M., Koliatsos, V., Wiley, R.G., and Heilman, C.J. 1995. Expression of m1-m4 muscarinic acetylcholine receptor proteins in rat hippocampus and regulation by cholinergic innervation. J. Neurosci. 15: 4077-4092.

Linster, C., Maloney, M., Patil, M., and Hasselmo, M.E. 2003. Enhanced cholinergic suppression of previously strengthened synapses enables the formation of self-organized representations in olfactory cortex. Neurobiol. Learn. Mem. 80: 302-314.

Miranda, M.I. and Bermudez-Rattoni, F. 1999. Reversible inactivation of the nucleus basalis magnocellularis induces disruption of cortical acetylcholine release and acquisition, but not retrieval of aversive memories. Proc. Natl. Acad. Sci. 96: 6478-6482.

Mrzljak, L., Levey, A.I., and Goldman-Rakic, P.S. 1993. Association of $\mathrm{m} 1$ and $\mathrm{m} 2$ muscarinic receptor proteins with asymmetric synapses in the primate cerebral cortex: Morphological evidence for cholinergic modulation of excitatory neurotransmission. Proc. Natl. Acad. Sci. 90: 5194-5198.

Naor, C. and Dudai, Y. 1996. Transient impairment of cholinergic function in the rat insular cortex disrupts the encoding of taste in conditioned taste aversion. Behav. Brain Res. 79: 61-67.

Oki, T., Takagi, Y., Inagaki, S., Taketo, M.M., Manabe, T., Matsui, M., and Yamada, S. 2005. Quantitative analysis of binding parameters of $[3 \mathrm{H}] \mathrm{N}$-methylscopolamine in central nervous system of muscarinic acetylcholine receptor knockout mice. Brain Res. Mol. Brain Res. 133: 6-11.

Orsetti, M., Casamenti, F., and Pepeu, G. 1996. Enhanced acetylcholine release in the hippocampus and cortex during acquisition of an operant behavior. Brain Res. 724: 89-96.

Price, J.L. 1973. An autoradiographic study of complementary laminar patterns of termination of afferent fibers to the olfactory cortex. J. Comp. Neurol. 150: 87-108.

Qian, J. and Saggau, P. 1997. Presynaptic inhibition of synaptic transmission in the rat hippocampus by activation of muscarinic receptors: Involvement of presynaptic calcium influx. $\mathrm{Br}$. J. Pharmacol. 122: 511-519.

Rouse, S.T., Marino, M.J., Potter, L.T., Conn, P.J., and Levey, A.I. 1999. Muscarinic receptor subtypes involved in hippocampal circuits. Life Sci. 64: 501-509.

Rouse, S.T., Edmunds, S.M., Yi, H., Gilmor, M.L., and Levey, A.I. 2000. Localization of $\mathrm{M}(2)$ muscarinic acetylcholine receptor protein in cholinergic and non-cholinergic terminals in rat hippocampus. Neurosci. Lett. 284: 182-186.

Saar, D., Grossman, Y., and Barkai, E. 1998. Reduced after-hyperpolarization in rat piriform cortex pyramidal neurons is associated with increased learning capability during operand-conditioning. Eur. J. Neurosci. 10: 1518-1523.

Saar, D., Grossman, Y., and Barkai, E. 1999. Reduced synaptic facilitation between pyramidal neurons in the piriform cortex after odor-learning. J. Neurosci. 19: 8616-8622.

Saar, D., Grossman, Y., and Barkai, E. 2001. Long-lasting cholinergic modulation underlies rule learning in rats. J. Neurosci. 21: $1385-1392$.

Sara, S.J., Roullet, P., and Przybyslawski, J. 1999. Consolidation of memory for odor-reward association: $\beta$-adrenergic receptor involvement in the late phase. Learn. Mem. 6: 88-96.

Schoenbaum, G. and Eichenbaum, H. 1995. Information coding in the rodent prefrontal cortex. 1. Single-neuron activity in orbito-frontal cortex compared with that in pyriform cortex. J. Neurophysiol. 74: $733-750$.

Staubli, U., Fraser, D., Kessler, M., and Lynch, G. 1986. Studies on retrograde and anterograde amnesia of olfactory memory after denervation of the hippocampus by enthorinal cortex lesions. Behav. Neural Biol. 46: 432-444.

Sutherland, R.J., Wishaw, I.O., and Regher, J. 1982. Cholinergic receptor blockade impairs spatial localization by use of distal cues in the rat. J. Comp. Physiol. Psychol. 96: 563-573.

Van der Zee, E.A. and Luiten, P.G.M. 1999. Muscarinic acetylcholine receptors in the hippocampus, neocortex and amygdala: A review of immunocytochemical localization in relation to learning and memory. Prog. Neurobiol. 58: 409-471.

Van der Zee, E.A., Compaan, J.C., Bohus, B., and Luiten, P.G. 1995. Alterations in the immunoreactivity for muscarinic acetylcholine receptors and colocalized PKC gamma in mouse hippocampus induced by spatial discrimination learning. Hippocampus 5: 349-362.

Van Koppen, C.J. and Kaiser, B. 2003. Regulation of muscarinic acetylcholine receptor signaling. Pharmacol. Ther. 98: 197-220.

Vogt, K.E. and Regehr, W.G. 2001. Cholinergic modulation of excitatory synaptic transmission in the CA3 area of the hippocampus. J. Neurosci. 21: $75-83$.

Volpicelli, L.A. and Levey, A.I. 2004. Muscarinic acetylcholine receptor subtypes in cerebral cortex and hippocampus. Prog. Brain Res. 145: $59-66$.

Waelbroeck, M., Robberecht, P., Chatelain, P., and Christophe, J. 1982. Rat cardiac muscarinic receptors. I. Effects of guanine nucleotides on high- and low-affinity binding sites. Mol. Pharmacol. 21: 581-588.

Wei, J., Walton, E.A., Milici, A., and Buccafusco, J.J. 1994. m1-m5 muscarinic receptor distribution in rat CNS by RT-PCR and HPLC. J. Neurochem. 63: 815-821.

Wu, L.G. and Saggau, P. 1994. Presynaptic calcium increased during normal synaptic transmission and paired-pulse facilitation, but not long-term potentiation in area CA1 of hippocampus. J. Neurosci. 14: $645-654$.

Received October 23, 2006; accepted in revised form January 23, 2007.

\section{Learning \& Memory}




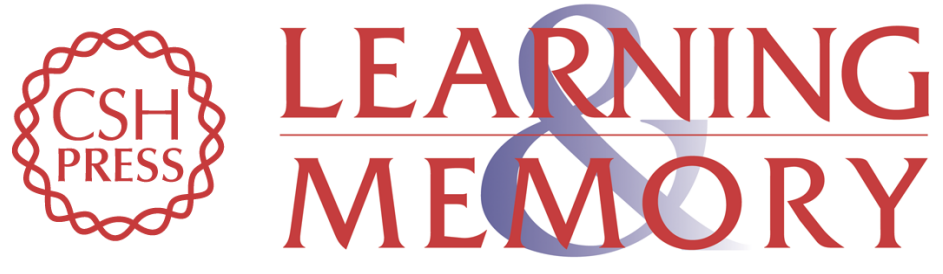

\section{Opposing effects on muscarinic acetylcholine receptors in the piriform cortex of odor-trained rats}

Drorit Saar, Moran Dadon, Marcela Leibovich, et al.

Learn. Mem. 2007, 14:

Access the most recent version at doi:10.1101//m.452307

References This article cites 39 articles, 14 of which can be accessed free at:

http://learnmem.cshlp.org/content/14/3/224.full.html\#ref-list-1

License

Email Alerting Receive free email alerts when new articles cite this article - sign up in the box at the Service top right corner of the article or click here. 